\title{
Antimicrobial and GC-MS Analyses of Stem and Root Extracts of Bidens pilosa Linn
}

\author{
CHRISTIANA O. AJANAKU ${ }^{1 *}$, JOHNBULL O. ECHEME², RAPHAEL C. MORDI', \\ OLAYINKA O. AJANI ${ }^{1}$, DANIEL U. OKERE ${ }^{3}$ and ABOLANLE A. KAYODE ${ }^{4}$
}

\author{
${ }^{1}$ Department of Chemistry, Covenant University, P.M.B. 1023, Ota, Ogun State, Nigeria. \\ ${ }^{2}$ Department of Chemistry, Michael Okpara University of Agriculture, Umudike, Abia State, Nigeria. \\ ${ }^{3}$ Department of Biochemistry, Covenant University, P.M.B. 1023, Ota, Ogun State, Nigeria. \\ ${ }^{4}$ Department of Pharmacognosy, Faculty of Pharmacy, University of Ibadan, Ibadan, Oyo State. \\ *Corresponding author E-mail: oluwatoyin.ajanaku@ covenantuniversity.edu.ng
}

http://dx.doi.org/10.13005/ojc/350247

(Received: December 03, 2018; Accepted: March 18, 2019)

\begin{abstract}
This study describes the qualitative phytochemical screening, antimicrobial and GC-MS analyses of the crude methanol extract of the stem and roots parts of Bidens pilosa partitioned between methanol, dichloromethane, ethyl acetate and hexane solvents. Phytochemical analysis indicated the presence of cardiac glycosides, terpenoids, flavonoids and alkaloids. Saponins were not found in any of the fractions of stem and root of $B$. pilosa. Antibacterial studies indicated that the lowest concentration $(6.25 \mathrm{mg} / \mathrm{mL})$ was achieved for Candida subtilis for the ethyl acetate fraction of the stem extract and hexane fraction of the root extract. Antimycobacterial test activity of these solvent fractions revealed that the hexane fraction of the root extract was susceptible to the bacterium isolate. Gas chromatography-Mass spectrometric study revealed the presence of the following compounds-cis-9-Hexadecenal, 2-hydroxyl ethyl (Z)-9-Octadecenoate, Octadecanal, Oleic acid, 4-(dimethylamino)-Benzaldehyde, 4,6,7-Trimethoxy-2,3-dihydrofuro(2,3-b)quinolone.
\end{abstract}

Keywords: Bidens pilosa, Antibacterial studies, Medicinal plants, Phytochemicals, Antimicrobial, Anti-mycobacterial, Gas chromatography-mass spectrometry.

INTRODUCTION

The application of modern medicine in the treatment of diverse infections has involved the prescription and administration of antibiotics. However, there has been reported side effects accompanying the use of antibiotics, such as: nausea, diarrhea, headache and rashes ${ }^{1}$. Moreover, use of adulterated drugs, overuse and incomplete use of prescribed medications have resulted in increasing rate of drug resistant antibiotics. This has led to increased interest in the use of medicinal plants as probable candidates for less toxic antimicrobials. The practice of medicinal plants symbolizes the ancient and most extensive form of medication that have been employed from time immemorial. Most natural medications obtained directly from plant or animal have been applied either as a preventive

This is an Open Access article licensed under a Creative Commons license: Attribution 4.0 International (CC- BY). Published by Oriental Scientific Publishing Company @ 2018

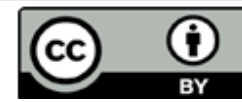


or curative means to maintain the human health system. Efforts made towards meeting the basic health care needs of the population, included the use of traditional medicine, which is widely practiced in many developing countries ${ }^{2}$. The therapeutic effects inherent in plants is attributed to the availability of some phytochemicals produced by plants. Some of the metabolites synthesized during the developmental stages of plants include phenolics, terpenoids, amines, alkaloids, glycosides and protein amino acids ${ }^{3}$. B. pilosa is a widely distributed herb that can be easily cultivated. Sometimes, it is considered a weed as a result of its abundant propensities. Reports on the application of B. pilosa has covered over 40 ailments. In India and Africa, the leaf part of $B$. pilosa is used as decoction to treat stomach disorders. Whole plant is used as decoction in Uganda, Cuba and China to treat diarrhea and asthma ${ }^{4}$, In China, the root part is used to treat malaria ${ }^{5}$. Previous studies on this plant identified some of its biological properties which includes: antibacterial $^{6}$, antimalarial ${ }^{5}$, anti-inflammatory ${ }^{7}$ and antioxidant ${ }^{8}$. Phytochemical and pharmacological activities employing the $B$. pilosa leaves ${ }^{9-10}$, roots $^{11}$, the stem ${ }^{12}$ and aerial parts ${ }^{13}$ have been published. A recent study carried out leaf, stem and root of this plant from six different locations ${ }^{14}$. In that study the authors observed that the bioactive composition of the extracts was dependent on the location where the plant was cultivated and concluded that the leaf parts exhibited highest antioxidant activity, followed by the root parts, while the stem exhibited the least activity. In another study on the antibacterial activity of the aqueous fractions of the leaf, stem and root of the plant; ${ }^{10}$ the authors concluded that the aqueous fraction of the leaf was more biologically active against bacteria. Earlier work on this plant on the in-vitro antibacterial, phytochemical, antimycobacterial and GC-MS analyses of B. pilosa leaf extract has been published ${ }^{9}$. The aim of this study is to evaluate the antimicrobial activity of the fractions and identify from GC-MS analysis the components of stem and root extracts of $B$. pilosa linn. The present study is to carry out a comparative analysis of the stem and root part of this plant with the previous work reported on the leaf extract of $B$. pilosa and also to validate the ethnobotanical claim of the application of this plant in the treatment of infectious disease such as tuberculosis.

\section{MATERIALS AND METHODS}

\section{Collection of Stem and Root parts of Bidens pilosa}

Plant samples of $B$. pilosa were locally sourced within Ado-Odo Ota of Ogun state, at location of $6^{\circ} 41^{\prime} N 3^{\circ} 41^{\prime}$. Forest Research Institute of Nigeria, authenticated the plant samples with a voucher number $\mathrm{FHI} 1100^{16}$. Clean water was used to thoroughly wash the stem and root samples of $B$. pilosa. Washed samples were air-dried for three weeks. Thereafter, samples were crushed into smaller particles using a milling machine.

\section{Extraction of the stem and root parts of Bidens pilosa}

At a temperature of $29^{\circ} \mathrm{C}$, cold maceration of the stem and root parts of $B$. pilosa was carried out for $72 \mathrm{~h}$ with methanol, employed for solvent extraction. The extract obtained was partitioned into: hexane, dichloromethane, ethyl acetate, methanol fractions.

\section{Phytochemical screening of the stem and root extracts of $B$. pilosa}

Standard qualitative methods was used to ascertain the presence of secondary metabolites in the stem and root parts of B. pilosa.

\section{Test for Carbohydrates}

Molisch's reagent ( $1 \mathrm{~mL}$ ), was added to $2 \mathrm{~mL}$ of plant extracts. Few drops of concentrated sulphuric acid was added to the mixture. Carbohydrate is confirmed by the formation of purple colour.

\section{Test for Tannins}

$2 \mathrm{~mL}$ of $5 \%$ ferric chloride was added to $1 \mathrm{~mL}$ of plant extracts. Greenish black colour indicated the presence of tannins.

\section{Test for Saponins}

$2 \mathrm{~mL}$ of distilled water was added to $2 \mathrm{~mL}$ of plant extracts and shaken in a graduated cylinder for 15 minutes lengthwise. Presence of saponins is shown by the formation of $1 \mathrm{~cm}$ layer of foam.

\section{Test for Flavonoids}

To $1 \mathrm{~mL}$ of the aqueous filtrate of plant extracts was added $5 \mathrm{~mL}$ of dilute ammonia solution followed by addition of concentrated sulphuric acid. Flavonoids is indicated by the appearance of yellow coloration. 


\section{Test for Alkaloids}

$2 \mathrm{~mL}$ of concentrated hydrochloric acid was added to $2 \mathrm{~mL}$ of plant extracts; to which few drops of Mayer's reagent was added. Alkaloids are indicated by the formation of green colour.

\section{Test for Anthocyanin and Betacyanin}

$1 \mathrm{~mL}$ of $2 \mathrm{M}$ sodium hydroxide was added to $2 \mathrm{~mL}$ of plant extracts and heated for $5 \mathrm{~min}$ at $100^{\circ} \mathrm{C}$. Yellow colour is formed; indicating the presence of betacyanin.

\section{Test for Quinones}

Concentrated sulphuric acid $(1 \mathrm{~mL})$, was added to $1 \mathrm{~mL}$ of plant extracts. Red colour is formed; indicating the presence of quinones.

\section{Test for Glycosides}

Addition of $3 \mathrm{~mL}$ of chloroform and $10 \%$ ammonia solution to $2 \mathrm{~mL}$ of plant extracts resulted in pink colour formation. Presence of glycosides is indicated.

\section{Test for Cardiac glycosides}

$2 \mathrm{~mL}$ of glacial acetic acid and few drops of $5 \%$ ferric chloride were added to $0.5 \mathrm{~mL}$ of plant extracts. To this mixture, $1 \mathrm{~mL}$ of concentrated sulphuric acid was added. Formation of brown ring at the interface showed that cardiac glycosides is present.

\section{Test for Terpenoids}

$2 \mathrm{~mL}$ of chloroform was added to $0.5 \mathrm{~mL}$ of plant extracts and concentrated sulphuric acid was carefully added. Formation of red brown colour at the interface indicated the presence of terpenoids.

\section{Test for Triterpenoids}

$1 \mathrm{~mL}$ of Libermann-Buchard Reagent (acetic anhydride + concentrated sulphuric acid) was added to $1.5 \mathrm{~mL}$ of plant extracts. Blue green colour is formed; indicating the presence of triterpenoids.

Test for Phenols $2 \mathrm{~mL}$ of distilled water was added to $1 \mathrm{~mL}$ of the plant extracts followed by few drops of $10 \%$ ferric chloride. Blue-black colour is formed, indicating the presence of phenols.

\section{Test for Coumarins}

$1 \mathrm{~mL}$ of $10 \%$ Sodium hydroxide was added to $1 \mathrm{~mL}$ of plant extracts. Yellow colour is formed, indicating the presence of coumarins.

\section{Test for steroids}

Chloroform (5 mL) was added to $2 \mathrm{~mL}$ of the extracts and filtered. $2 \mathrm{~mL}$ of acetic anhydride was added to $2 \mathrm{~mL}$ of filtrate with $2 \mathrm{~mL}$ of sulphuric acid. Change of colour from violet to blue or green indicates the presence of steroids.

\section{Test for Acids}

Sodium bicarbonate solution was added to $1 \mathrm{~mL}$ of extracts. Presence of acids is indicated by the formation of effervescence.

\section{Antibacterial activity of Bidens pilosa stem and root extracts}

Antibacterial activity against Candida albicans, Rhizopus, Pseudomonas aeruginosa, Serratia spp, Micrococcus varians, Staphylococcus aureus, Escherichia coli, Bacillus spp was carried out using extracts of the stem and root parts of $B$. pilosa. Medium used for these isolates was Sabouraud dextrose agar.

\section{Minimum Inhibitory Concentration (MIC) Determination}

Minimum inhibitory concentration of the stem extracts and root extracts of $B$. pilosa using microplate dilution method ${ }^{8}$ was employed against test isolates: Candida albicans, Rhizopus, Pseudomonas aeruginosa, Bacillus subtilis, Escherichia coli, Klebsiella pneumonia and Staphylococcus aureus, Concentrations of the extracts were reformed to $50,25,12.5,6.25,3.125$ and $1.562 \mathrm{mg} / \mathrm{mL}$. Control used as standard antibiotics was gentamycin having a concentration of $10 \mu \mathrm{g}$. Test organisms of $0.5 \%$ McFarland standard were seeded on a sterile nutrient agar plates. Wells of about $9 \mathrm{~mm}$ in diameter was bored into the agar plate using a sterile cork borer. $0.2 \mathrm{~mL}$ of each extract of different concentrations was inoculated into the bored wells. After incubation at $37^{\circ} \mathrm{C}$ for $24 \mathrm{~h}$, observations were made for growth and death of test organisms.

\section{Anti-mycobacterial susceptibility test}

Anti-mycobacterial susceptibility test, using the proportion method on an L-J medium was employed using standard procedures. Standard chemicals were procured to prepare the mycobacterium tuberculosis isolates. The isolates were introduced in-vitro against stem and root extracts/fractions of $B$. pilosa, rifampicin (drug susceptible) at a concentration of $40 \mu \mathrm{g}$ and 
levofloxacin (drug resistant) at a concentration of 200 $\mu \mathrm{g}$ on an L-J medium. Thereafter, incubation took place at a temperature of $37^{\circ} \mathrm{C}$. After the $28^{\text {th }}$ and $42^{\text {nd }}$ day, readings were taken in quintuples for drug susceptible and duplicates for drug resistance. Mean reduction in number of colonies on test samples when compared to drug-free controls was employed in evaluating the percentage resistance in the L-J medium.

\section{Quantitative phytochemical evaluation}

Phenols $0.8 \mathrm{~mL}$ of Folin-Ciocalteu's reagent was added to $0.2 \mathrm{~mL}$ of sample in a test tube. $2 \mathrm{~mL}$ of $7.5 \% \mathrm{Na}_{2} \mathrm{CO}_{3}$ was added and mixed. Distilled water $(7 \mathrm{~mL})$ was added; after which it was incubated in the dark for 2 hour. Absorbance was taken at $765 \mathrm{~nm}$.

\section{Flavonoid}

To $0.5 \mathrm{~mL}$ of each extract solution was added $2.5 \mathrm{~mL}$ of $95 \%$ ethanol. To this mixture was added $0.1 \mathrm{~mL}$ of $1 \mathrm{M}$ potassium acetate, $2.8 \mathrm{~mL}$ distilled water and $0.1 \mathrm{~mL}$ of $10 \% \mathrm{AlCl}_{3} \cdot 6 \mathrm{H}_{2} \mathrm{O}$. At room temperature, mixture was incubated for $45 \mathrm{~min}$; after which absorbance was taken at $415 \mathrm{~nm}$.

\section{Steroid}

Sulphuric acid (4 N, $2 \mathrm{~mL}$ ) and iron(III) chloride $(0.5 \% \mathrm{w} / \mathrm{v}, 2 \mathrm{~mL})$, were added to $1 \mathrm{~mL}$ of each extract. To this mixture was added potassium hexacyanoferrate(III) solution $(0.5 \% \mathrm{w} / \mathrm{v}, 0.5 \mathrm{~mL})$. In a water bath, the mixture is kept at $70^{\circ} \mathrm{C}$ for 30 min with constant shaking; after which absorbance is taken at $780 \mathrm{~nm}$.

\section{Alkaloid}

$100 \mathrm{~mL}$ of ethanolic acetic acid was added to $2.5 \mathrm{~g}$ of the sample into a $250 \mathrm{~mL}$ beaker. Mixture is allowed to incubate for 4 hours. It is filtered and heated to one-quarter of its original volume. Ammonium hydroxide solution was added in drops until precipitation is complete. Collected precipitate was washed with dilute ammonia solution; after which it was filtered, dried and weighed.

\section{GC-MS analysis of Bidens pilosa stem and root extracts}

The combined gas chromatography and mass spectrometry analysis was carried out on the stem extracts as well as root extracts of the $B$. pilosa plant; using Agilent equipment $7890 \mathrm{~A}$, with software by Mass Hunter to identify the volatile compounds from the plant parts. The equipment consists of inert capillary tube having a dimension of $30 \mathrm{~mm} \times 0.25 \mathrm{~mm}$ ID $\times 0.25 \mu \mathrm{m}$ film; a carrier gas of Helium flowing at $1.0 \mathrm{~mL} / \mathrm{min}$. At $250^{\circ} \mathrm{C}$, the injector was operated; while the temperature of the oven was increased gradually from $50^{\circ} \mathrm{C}$ to $300^{\circ} \mathrm{C}$ for 10 minute. The NIST library data was employed to identify the components from the peak areas in the gas chromatography.

\section{RESULTS AND DISCUSSION}

\section{Results}

Table 1 shows the presence of secondary metabolites in the stem extracts of B. pilosa, which include tannins, alkaloids, cardiac glycosides, terpenoids, phenols, coumarins and steroids. In all the solvent fractions, terpenoids, cardiac glycosides and alkaloids were found present. Saponins were absent from all the solvent fractions. This is in contrast to previous studies. This may be due to difference in ecological factors. Flavonoids, carbohydrates were observed to be present in the hexane fraction and methanolic fraction. The ethyl acetate fractions as well as dichloromethane fraction showed the presence of phenols and tannins. All the solvents used in this study were of different polarities so as to identify the best solvents for extracting secondary metabolites from $B$. pilosa. Table 2 shows the phytochemicals in the root of $B$. pilosa. Saponins were absent from all the solvent fractions in root extracts. Steroids are absent in the methanolic fraction. However, the hexane, DCM and ethyl acetate fractions indicated the presence of steroids. Alkaloids, cardiac glycosides, terpenoids are found in all the solvent fractions of the root extract of B. pilosa.

Table 3 shows the total tannin, flavonoids, alkaloids and phenols as contained in dichloromethane, hexane, methanol and ethyl acetate fractions of the stem of B. pilosa. Ethyl acetate fraction contains more of the total steroids and total phenols, while the DCM fraction contains more of the total tannins. Total flavonoids is more abundant in the hexane fraction while the methanol fraction contains more of the total alkaloids. In Table 4 , the total tannin and total phenol is well indicated in the ethyl acetate fraction. Total flavonoids can be found more prominent in the hexane fraction of the root part of $B$. pilosa. Total alkaloids are well indicated in the methanolic fractions while the total steroids are more abundant in the hexane fraction. 
Table 1: Stem fractions of B. pilosa Showing Intensities of Phytochemicals Present

\begin{tabular}{lcccc}
\hline Constituents & Hexane & $\begin{array}{c}\text { Intensity } \\
\text { Dichloromethane } \\
\text { Fraction }\end{array}$ & $\begin{array}{c}\text { Ethyl Acetate } \\
\text { Fraction }\end{array}$ & $\begin{array}{c}\text { Methanol } \\
\text { Fraction }\end{array}$ \\
\hline Carbohydrates & ++ & - & - & ++ \\
Tannins & - & ++ & ++ & ++ \\
Saponins & - & - & - & - \\
Flavonoids & ++ & - & ++ & ++ \\
Alkaloids & ++ & ++ & - & + \\
Anthocyanin \& Betacyanin & ++ & - & - & + \\
Quinones & ++ & - & ++ & ++ \\
Glycosides & - & ++ & ++ & ++ \\
Cardiac glycoside & ++ & + & ++ & - \\
Terpenoids & ++ & + & - & - \\
Triterpenoids & ++ & + & ++ & - \\
Phenols & - & ++ & - & - \\
Coumarins & ++ & - & + \\
Steroids & ++ & - & ++ \\
Acids & - & ++ & + \\
\hline
\end{tabular}

KEY: + = trace, $++=$ moderate, $\quad+++=$ intense, $\quad-=$ not present

Table 2: Root fractions of B. pilosa with intensities of Secondary metabolites present

\begin{tabular}{lcccc}
\hline Constituents & Hexane & $\begin{array}{c}\text { Intensity } \\
\text { Dichloromethane } \\
\text { Fraction }\end{array}$ & $\begin{array}{c}\text { Ethyl Acetate } \\
\text { Fraction }\end{array}$ & $\begin{array}{c}\text { Methanol } \\
\text { Fraction }\end{array}$ \\
\hline Carbohydrates & + & - & - & + \\
Tannins & - & + & + & + \\
Saponins & - & - & - & - \\
Flavonoids & + & - & + & + \\
Alkaloids & + & + & - & + \\
Anthocyanin \& Betacyanin & + & - & - & - \\
Quinones & + & + & - & + \\
Glycosides & - & - & + & + \\
Cardiac glycoside & + & + & + & + \\
Terpenoids & + & + & + & + \\
Triterpenoids & + & + & + & - \\
Phenols & - & + & - & - \\
Coumarins & + & + & + & - \\
Steroids & + & + & - & - \\
Acids & - & - & & - \\
\hline
\end{tabular}

KEY: $+=$ trace,$++=$ moderate,$\quad+++=$ intense,$\quad-=$ not present

Table 3: B. pilosa stem extract Showing Quantitative Phytochemical Analysis

\begin{tabular}{|c|c|c|c|c|c|}
\hline Fractions & Total Alkaloid (\%) & Total Flavonoid (\%) & Total Phenol (\%) & Total Tannin (\%) & Total Steroids (\%) \\
\hline Hexane & 0.32 & 0.42 & - & - & 0.22 \\
\hline DCM & 0.20 & 0.20 & 0.24 & 0.64 & - \\
\hline Ethyl acetate & - & - & 0.32 & 0.36 & 0.35 \\
\hline Methanol & 0.36 & 0.23 & - & 0.42 & - \\
\hline
\end{tabular}

Table 4: B. pilosa root extract Showing Quantitative Phytochemical Analysis

\begin{tabular}{lccccc}
\hline Fractions & Total Alkaloid (\%) & Total Flavonoid (\%) & Total Phenol (\%) & Total Tannin (\%) & Total Steroids (\%) \\
\hline Hexane & 0.12 & 0.35 & - & - & 0.17 \\
DCM & 0.08 & - & 0.13 & 0.05 & - \\
Ethyl acetate & - & - & 0.20 & 0.29 & 0.06 \\
Methanol & 0.24 & 0.23 & - & 0.02 & - \\
\hline
\end{tabular}


Antimicrobial analysis of stem and root fractions of Bidens pilosa

Table 5 shows the stem portion of B. pilosa, where the methanolic fraction shows activity against Bacillus subtilis. Dichloromethane, ethyl acetate and methanol fractions all indicated activity against Candida albicans. Table 6 indicates that the methanolic fraction of the root part of $B$. pilosa showed activity against Bacillus subtilis. All the solvents exhibited activity against Candida albicans. The hexane fraction showed activity against Rhizopus. From Table 7, the evaluation of antimicrobial in the stem of $B$. pilosa revealed the activities of methanol, dichloromethane and ethyl acetate against Candida albicans with the ethyl acetate fraction showing the lowest concentration against Candida albicans at $6.25 \mathrm{mg} / \mathrm{L}$. From the same table, the hexane fraction of the root part of $B$. pilosa, showed the minimum concentration at $6.25 \mathrm{mg} / \mathrm{L}$ against Candida albicans. From Table 8 , the evaluation of the antimicrobial in the root of $B$. pilosa indicated the activity of ethyl acetate and hexane fractions against Candida albicans. The hexane fraction shows more activity against Candida albicans at $6.25 \mathrm{mg} / \mathrm{L}$.

Table 5: Stem fractions of $B$. pilosa Showing Zones of inhibition (in $\mathrm{mm}$ ) against selected microorganisms

\begin{tabular}{lccccc}
\hline & \multicolumn{5}{c}{ Zone of inhibition in millimetres } \\
Organism & $\begin{array}{c}\text { Hexane } \\
\text { fraction }\end{array}$ & $\begin{array}{c}\text { Dichloromethane } \\
\text { fraction }\end{array}$ & $\begin{array}{c}\text { Ethyl acetate } \\
\text { fraction }\end{array}$ & $\begin{array}{c}\text { Methanol } \\
\text { fraction }\end{array}$ & $\begin{array}{c}\text { Control } \\
\text { (Gentamycin) }\end{array}$ \\
\hline Bacillus subtilis & - & 12 & - & 18 & 15 \\
Escherichia coli & - & - & - & - & 8 \\
Klebsiella pneumoniae & 10 & - & - & - & 16 \\
Pseudomonas aeruginosa & - & - & - & - & 10 \\
Staphylococcus aureus & - & 40 & - & 38 & - \\
Candida albicans & - & - & - & - & 8 \\
Rhizopus & & & & & - \\
\hline
\end{tabular}

Table 6: Root fractions of B. pilosa Showing Zones of inhibition (in $\mathrm{mm}$ ) against selected microorganisms

\begin{tabular}{lccccc}
\hline \multirow{2}{*}{ Organisms } & \multicolumn{5}{c}{ Zone of inhibition in millimetres } \\
& $\begin{array}{c}\text { Hexane } \\
\text { fraction }\end{array}$ & $\begin{array}{c}\text { Dichloromethane } \\
\text { fraction }\end{array}$ & $\begin{array}{c}\text { Ethyl acetate } \\
\text { fraction }\end{array}$ & $\begin{array}{c}\text { Methanol } \\
\text { fraction }\end{array}$ & $\begin{array}{c}\text { Control } \\
\text { (Gentamycin) }\end{array}$ \\
\hline Bacillus subtilis & - & - & 11 & 18 & 12 \\
Escherichia coli & - & - & 11 & - & 11 \\
Klebsiella pneumoniae & - & - & 10 & - & - \\
Pseudomonas aeruginosa & - & - & 13 & - & - \\
Staphylococcus aureus & - & - & 38 & 38 & - \\
Candida albicans & 40 & -25 & - & - & - \\
Rhizopus & 25 & & & - & 18 \\
\hline
\end{tabular}

Table 7: Minimum Inhibitory Concentration of Stem Fractions of Bidens pilosa for Selected Microorganism

\begin{tabular}{lccc}
\hline Organisms & Methanol Fraction $(\mathrm{mg} / \mathrm{mL})$ & Dichloromethane Fraction $(\mathrm{mg} / \mathrm{mL})$ & Ethyl acetate Fraction $(\mathrm{mg} / \mathrm{mL})$ \\
\hline Candida albicans & 12.5 & 12.5 & 6.25 \\
\hline
\end{tabular}

Table 8: Minimum Inhibitory Concentration of Root Fractions of Bidens Pilosa for Selected Microorganism

\begin{tabular}{lcc}
\hline Organisms & Ethyl acetate Fraction $(\mathrm{mg} / \mathrm{mL})$ & Hexane fraction $(\mathrm{mg} / \mathrm{mL})$ \\
\hline Candida albicans & 12.5 & 6.25 \\
\hline
\end{tabular}


Antimycobacterial analysis of stem and root fractions of Bidens Pilosa

Table 9 shows the results obtained from the in-vitro anti-mycobacterial analysis of the stem and root parts of $B$. pilosa plant using the proportion method. The crude, hexane, methanol and chloroform fractions of the stem part of B. pilosa indicated resistance to the anti-mycobacterial test; while only the hexane fraction of the root part indicated sensitivity against the test organism. Controls on the in-vitro analysis are $40 \mu \mathrm{g}$ of drug susceptible (Rifampicin) and $200 \mu \mathrm{g}$ of drug resistant (Levofloxacin). Where DS-MTB represent the drug susceptible mycobacterium tuberculosis, while DR-MTB in the table represent drug resistant mycobacterium tuberculosis.

Table 9: Stem extract and Root extract of Bidens pilosa against Mycobacterium tuberculosis isolate showing the availability of strains (resistant and sensitive)

\begin{tabular}{|c|c|c|c|c|c|c|c|c|c|}
\hline Bidens pilosa & Fractions & DS-MTB 1 & DS-MTB 2 & DS-MTB 3 & DS-MTB 4 & DS-MTB 5 & DR-MTB 1 & DR-MTB 2 & H37Rv \\
\hline \multirow[t]{4}{*}{ Stem } & Crude extract & $S$ & $\mathrm{R}$ & $\mathrm{R}$ & $\mathrm{R}$ & $\mathrm{R}$ & $\mathrm{R}$ & $\mathrm{R}$ & $S$ \\
\hline & Chloroform & $\mathrm{R}$ & $\mathrm{S}$ & $S$ & $\mathrm{R}$ & $\mathrm{R}$ & $\mathrm{R}$ & $\mathrm{R}$ & $\mathrm{R}$ \\
\hline & Methanolic & $\mathrm{R}$ & $\mathrm{R}$ & $\mathrm{R}$ & $\mathrm{R}$ & $\mathrm{R}$ & $\mathrm{R}$ & $\mathrm{R}$ & $\mathrm{R}$ \\
\hline & Hexane & $\mathrm{R}$ & $\mathrm{R}$ & $\mathrm{R}$ & $\mathrm{R}$ & $\mathrm{R}$ & $\mathrm{R}$ & $\mathrm{R}$ & $\mathrm{R}$ \\
\hline \multirow[t]{4}{*}{ Root } & Crude extract & $\mathrm{R}$ & $\mathrm{R}$ & $\mathrm{R}$ & $\mathrm{R}$ & $\mathrm{R}$ & $\mathrm{R}$ & $\mathrm{R}$ & $\mathrm{R}$ \\
\hline & Chloroform & $\mathrm{R}$ & $\mathrm{R}$ & $\mathrm{R}$ & $\mathrm{R}$ & $\mathrm{R}$ & $\mathrm{R}$ & $\mathrm{R}$ & $\mathrm{R}$ \\
\hline & Methanolic & $\mathrm{R}$ & $\mathrm{R}$ & $\mathrm{R}$ & $\mathrm{R}$ & $\mathrm{R}$ & $\mathrm{R}$ & $\mathrm{R}$ & $\mathrm{R}$ \\
\hline & Hexane & $S$ & $\mathrm{~S}$ & $S$ & $S$ & $S$ & $S$ & $S$ & $S$ \\
\hline
\end{tabular}

Key: S - Sensitive; R - Resistance

Figure 1 illustrates the presence of various components of the stem of $B$. pilosa with different retention times. The nature and structure of the compounds are analyzed by the mass spectrometer as the compounds are eluted at different times. From Table 9, compounds identified by the GC-MS analysis for the stem part of B. pilosa include; cis-9Hexadecenal, 2-hydroxyl ethyl (Z)-9-Octadecenoate, Octadecanal and Oleic acid. Fig. 2 shows the presence of various components of the root of $B$. pilosa with different retention times. Some of the compound from the root part of B. pilosa by GC-MS analysis includes: 4-(dimethylamino)-Benzaldehyde, 4,6,7-trimethoxy-2,3-dihydrofuro(2,3-b)quinolone.

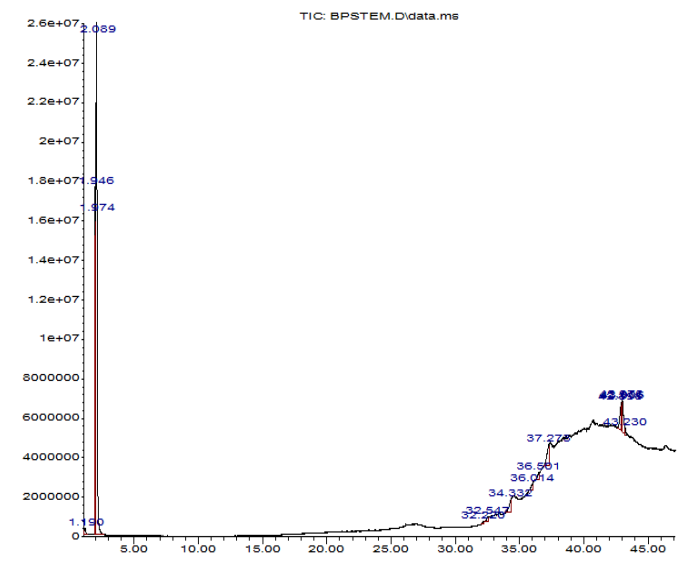

Fig. 1. Chromatogram of methanolic extract of B. pilosa Stem

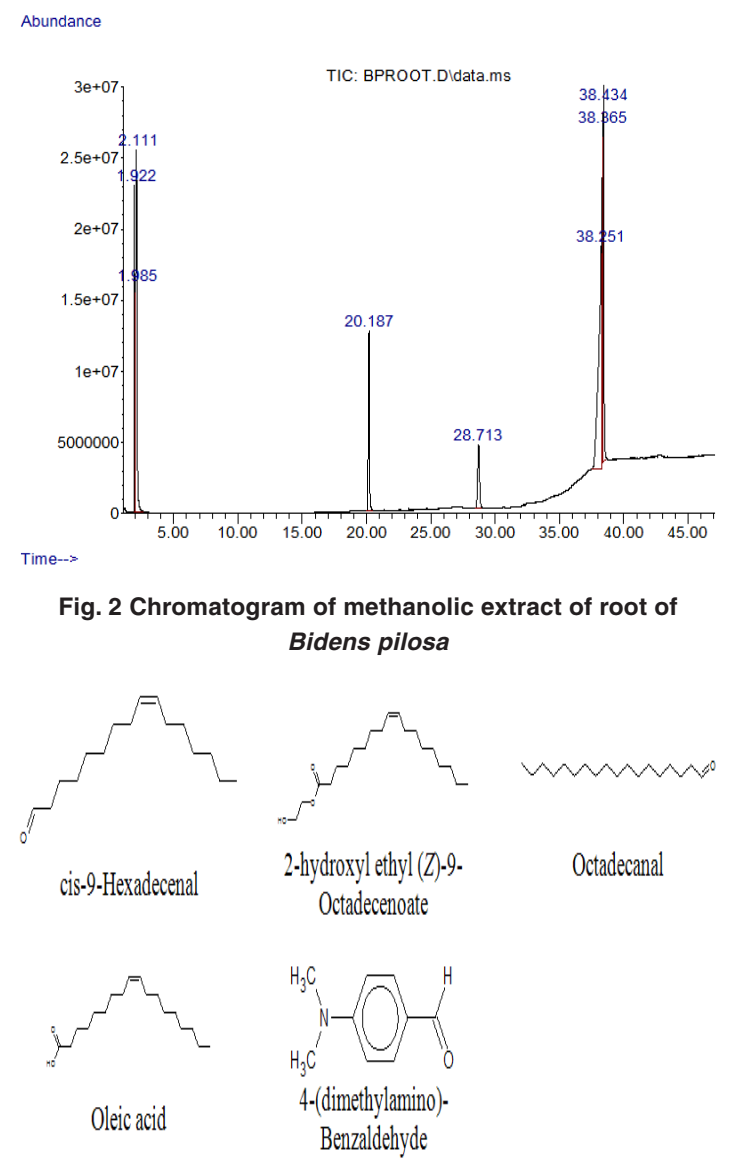

Fig. 3. Structures of Compounds Identified by GC-MS 
Table 10: Gas Chromatography-Mass spectrometry analysis of methanolic extract of stem of Bidens pilosa

\begin{tabular}{lcccc}
\hline $\mathrm{S} / \mathrm{n}$ & Ret. time & Compounds & Molecular weight $(\mathrm{g} / \mathrm{mol})$ & Molecular formula \\
\hline 1. & 1.19 & cis-9-Hexadecenal & 238.415 & $\mathrm{C}_{16} \mathrm{H}_{30} \mathrm{O}$ \\
2. & 34.332 & 2-hydroxylethyl(Z)-9-Octadecenoate & 326.513 & $\mathrm{C}_{20} \mathrm{H}_{38} \mathrm{O}_{3}$ \\
3. & 36.501 & Octadecanal & 268.478 & $\mathrm{C}_{18} \mathrm{H}_{36} \mathrm{O}$ \\
4. & 43.230 & Oleic Acid & 282.255 & $\mathrm{C}_{18} \mathrm{H}_{34} \mathrm{O}_{2}$ \\
\hline
\end{tabular}

Table 11: Gas Chromatography-Mass spectrometry analysis of methanolic root extract of Bidens pilosa

\begin{tabular}{lcccc}
\hline $\mathrm{S} / \mathrm{N}$ & Ret. time & Compounds & Molecular weight (g/mol) & Molecular formula \\
\hline 1. & 20.187 & 4-(dimethylamino)-Benzaldehyde & 149.190 & $\mathrm{C}_{9} \mathrm{H}_{11} \mathrm{NO}$ \\
2. & 28.713 & $4,6,7-$ Trimethoxy-2,3-dihydrofuro(2,3-b)quinoline & 261.277 & $\mathrm{C}_{14} \mathrm{H}_{15} \mathrm{NO}_{4}$ \\
\hline
\end{tabular}

\section{DISCUSSION}

The presence of the following secondary metabolites was indicated in the stem and root extracts of $B$. pilosa: flavonoids, alkaloids, terpenoids, phenols, glycosides and tannins. This is confirmed by previous studies ${ }^{15}$. Cardiac glycoside compounds, though produced in small amounts in plants, are generally useful in the treatment of congestive heart failure. Cardiac glycosides in the stem and root parts of B. pilosa, could be the factor that explains its use in folk medicine as an antihypertensive agent and smooth muscle relaxant; with studies now confirming its efficacy ${ }^{16}$.

Alkaloids are commonly distributed in plants and play a significant role in the defence systems against pathogens and animals. Medicinally, they are known as stimulants, local anesthetics, anti-bacterial, anti-hypertensive and analgesics. This explains the use of B. pilosa in the treatment of headaches and pains ${ }^{17}$.

Flavonoids are a group of natural metabolites which can be found in several parts of a plant such as flowers, leaves, stem or root. They are responsible for the colour and aroma of flowers and fruits so as to attract pollinators resulting in dispersion of fruits and seeds for growth and development of seedlings. Consisting of diverse phenolic structures, flavonoids are made up of several subgroups, which include flavones, Chalcones, isoflavones and flavonols. They are known to contain wide spectrum of health promoting effects ranging from anti-inflammatory, anti-oxidative, anti-mutagenic, anti-carcinogenic to anti-viral and vasodilating actions. The presence of flavonoids in the stem and root parts of B. pilosa validates its traditional use to treat malaria, wounds, colds and flu ${ }^{18}$.

Tables 2 and 3, reveal the quantitative phytochemicals present in the stem and root parts of $B$. pilosa. The table reveals hexane as a good solvent suitable for the extraction of flavonoids from the stem and root part of B. pilosa. For the total alkaloids, hexane and methanol solvents gave a high yield in the stem part of the plant; while methanol solvent is more suitable for extraction of high yield of alkaloids from the root part of $B$. pilosa. For a high yield of phenols from both stem and root, ethyl acetate is a very suitable solvent for extraction.

The antimicrobial analysis of the stem of B. pilosa showed that only the methanol and ethyl acetate solvents of the stem showed activity against $B$. subtilis and K. pneumonia. The ethyl acetate solvent of the root parts showed higher activities against both the Gram-positive and Gram-negative bacteria strains than other solvents. This is in contrast with previous study ${ }^{11}$ on the antimicrobial studies on the root parts of a South African eco-type of B. pilosa. This may be as a result of different ecological environments of the plants under study. Earlier study of the leaf part of B. pilosa ${ }^{9}$, however, revealed methanol solvent as having higher activity against the bacteria strains more than the other solvents employed. This result aligns with earlier work carried out, where the whole plant extracts inhibited the growth of both Gram-positive and Gram-negative bacteria ${ }^{19}$.

The ethyl acetate extracts from the stem part of B. pilosa showed higher activity against 
Candida albicans at $6.25 \mathrm{mg} / \mathrm{mL}$; the hexane extract of the root part of $B$.pilosa exhibited activity against Candida albicans at same concentration. Earlier study on the leaf part of $B$. pilosa, showed activity against Candida albicans from the methanol extract also at $6.25 \mathrm{mg} / \mathrm{mL}$ and from dichloromethane at $3.125 \mathrm{mg} / \mathrm{mL}$. All the solvent extracts from the stem part of the plant did not show any activity against Rhizopus; while the hexane extract from the root part showed a high activity compared to the control at $25 \mathrm{~mm}$. This study is in compliance with a similar study on the root extracts from $B$. pilosa from South African ecotype ${ }^{11}$ which showed a moderate activity against Candida albicans.

Results obtained from the anti-mycobacterial analysis of the stem and root parts of B. pilosa using the proportion method revealed that the hexane fraction of the root part of $B$. pilosa shows sensitivity against the mycobacteria isolates while the stem parts showed resistance. This result complements findings from earlier study on the anti-mycobacterial activity of the leaf of $B$. pilosa ${ }^{9}$. Some studies on medicinal plants considered for treatment against infectious diseases such as tuberculosis by traditional medicine in South Africa ${ }^{20}$ was reported. From this study, B. pilosa was listed among several plants that has been applied locally in the treatment of tuberculosis, by adding water to the air-dried leaf, which is boiled for $45 \mathrm{~min}$ and taken orally daily for three weeks.

From Table 10, compounds identified by the gas-column spectroscopy indicate the presence of unsaturated fatty acids in the plant under study; which improves the blood lipid profile and reduces cardiovascular related issues ${ }^{21}$. In Table 11, the presence of 4-(dimethylamino)-Benzaldehyde and 4,6,7-Trimethoxy-2,3-dihydrofuro(2,3-b)quinolone ${ }^{22}$ which were also identified as shown in Fig. 3. Presence of quinolone derivative could relate to the anti-malaria property of the root part of the plant. This study has been able to validate the employment of this medicinal plant and also throw more light on the bioactive parts of the plant. The formula, name, molecular weight and structure of compounds identified by gas column mass spectrometry analysis were determined by comparing with the spectra of components stored in the database of National Institute Standard and Technology library.

\section{CONCLUSION}

Preliminary phytochemical analysis has identified cardiac glycosides, alkaloids, flavonoids existing within the stem and root parts of $B$. pilosa. The presence of these phytochemicals in the plant under study, have been responsible for its therapeutic properties; such as anti-malaria, analgesic, antiinflammatory, anti-hypertensive and the anti-oxidant activities of the medicinal plant. The plant, B. pilosa, from this present study shows its activity against Gram-positive and Gram-negative bacteria as well as against fungi. This validates the antibacterial and antifungal properties of $B$. pilosa as it is widely applied locally in the treatment of wounds, urinary tract infections, cough, respiratory tract infections or stomach ulcers. The in vitro anti-mycobacterial analysis revealed the hexane fraction of the root part as being the bioactive part of the plant under study; while the stem part is shown to be inactive.

\section{Significance statement}

This study confirmed the antibacterial and antifungal properties of B. pilosa, particularly the West African eco-type. It also established the antimycobacterial activity of the root part of the plant; thereby affirming its potency in its application to treat respiratory tract infections such as tuberculosis. The study contributes to the arsenal of potential drugs in combating drug resistant bacteria.

\section{ACKNOWLEDGMENT}

This work was supported by the management of Covenant University, Ota under the Covenant University Center for Research, Innovation and Development, support grant. Appreciation goes to the Chemistry Department, Ahmadu Bello University, Zaria for use of laboratory facilities and Central Analytical facilities, Stellenbosch University, South Africa.

\section{REFERENCES}

1. Anyanwu, M.U.; Okoye, R.C. Journal of intercultural Ethnopharmacology., 2017, 6(2), 240-259.
2. Arthur, G.D.; Naidoo, K. K.; Coopoosamy, R. M. Journal of Medicinal Plants Research., 2012, 6(17), 3282-3287. 
3. Singh, R. Journal of Plant Sciences., 2015; 3(1-1), 50-55.

4. Bartolome, A.; Villasenor, M.; Yang, W. Evidence-Based Complementary and Alternative Medicine., 2013, 1, 51.

5. Oliveira, F.Q.; Andrade-Neto, V.; Krettli, A.U.; Brandao, M.G.L. J Ethnopharmacol., 2004, 93, 39-42.

6. Deba, F.; Xuan, T.D.; Yasuda, M.; Tawata, S. Food Control., 2008, 19, 346-352.

7. Brandao, M.G.L.; Krettli, A.U.; Soares, L.S.R.; Nery, C.G.C.; Marinuzzi, H.C. Journal of Ethnopharmacology., 1997, 57, 131-138.

8. Chiang, Y.M.; Chuang, D.Y.; Wang, S.Y.; Kuo, Y.H.; Tsai, P.W.; Shyur, L.F.; J. Ethnopharmacol., 2004, 95, 409-419.

9. Ajanaku, C.; Echeme, J.; Mordi, R.; Bolade, O.; Okoye, S.; Jonathan, H.; Ejilude, O. J. Microbiol Biotech Food Sci., 2018, 8(1), 721-725.

10. Lawal, O.A.; Amisu, K.O.; Akinyemi, S. K.; Sanni, A. A.; Simelane, M. B. C; Mosa, R. A; Opoku, A. R. British Microbiology Research Journal., 2015, 8(4), 525-531.

11. Ashafa, A.O.T.; Afolayan, A. J. Journal of Medicinal Plant Research., 2009, 3(8), 568-572.

12. Ogunbinu, A.O.; Flamini, G.; Cioni, P.L.; Adebayo, M.A.; Ogunwande, I.A. Nat. Prod. Commun., 2009, 4, 573-578.

13. Wang, R.; Wu, Q.X.; Shi, Y.P. Planta Med., 2010, 76, 893-896.
14. Cortés-Rojas, Diego .F.; Chagas-Paula; Daniela A.; Da Costa; Fernando B.; Souza; Claudia, R. F; Oliveira; Wanderley, P. Revista Brasileira de Farmacognosia., 2013, 23, 1, 28-35.

15. Ladan, Z.; Amupitan, J.O.; Oyewale, O.A.; Ayo, R.G.; Temple, E.; Ladan, E.O. African Journal of Pure and Applied Chemistry., 2014, 8(5), 83-88.

16. Connelly, P. Journal of The Australian Traditional-Medicines Society., 2009, 15(2), 77-79.

17. Ezeonwumelu, J.O.C.; Ntale, M.; Ogbonnia, S.O.; Agwu, E.; Tanayen, J.K.; Adedeji, A.A.; Okonkwo, C.O.; Akunne, A.A.; Ebosie, J.C.; Byarugaba, F. Pharmacology \& Pharmacy., 2018, 9, 175-192.

18. Silva, F.L.; Fischer, D.C.; Tavares, J.F.; Silva, M.S.; De-Athayde-Filho, P.F.; Barbosa-Filho, J.M. Molecules., 2011, 16(2), 1070-1102.

19. Khan, M.R.; Kihara, M.; Omoloso, A.D. Fitoterapia., 2001, 72, 662-665.

20. Lawal, I.O.; Grierson, D.S.; and Afolayan, A.J.; 2014. Evidence-Based Complementary and Alternative Medicine. Article ID 735423., 2014, 2014. 11.

21. Ander, B. P.; Dupasquier, C. M.; Prociuk, M. A.; Pierce, G. N. Experimental and Clinical Cardiology., 2003, 8(4), 164-72.

22. National Institute of Advanced Industrial Science and Technology (AIST). National Metrology Institute of Japan (NMIJ). 